Томаска Алена Георгиевна

научный сотрудник отдела истории и этносоциологии Института гуманитарных исследований и проблем малочисленных народов Севера Сибирского отделения Российской академии наук

\section{ЭТНОКУЛЬТУРНЫЕ РЕСУРСЫ ИНТЕГРАЦИИ ТРУДОВЫХ МИГРАНТОВ ЯКУТИИ}

\section{Аннотация:}

Статья посвящена анализу этнокультурных ре сурсов интеграции трудовых мигрантов в Рес публике Саха (Якутия). Рассмотрены факторы, формирующие своеобразие развития современных миграционных процессов региона, структура трудовой миграции, статистические материалы о миграционном движении, результаты социологического исследования. Эмпирические данные проанализированы в рамках социально-коммуникативного контекста среди трудовых мигрантов и количественных аналитических процедур социологии миграции принимающего сообщества. Omмечается, что этнокультурные установки трудовых мигрантов с точки зрения их интеграции в принимающее сообщество ограниченны. Этнокультурные ресурсы такой интеграции сдерживаются проявлением у мигрантов мотивов-целей, связанных исключительно с зарабатыванием денег, разработкой сепаратных, ограниченных земляческими сетями, дифференцирующих стратегий взаимодействия с местным населением. Оно в большей степени воспринимается ими как экономический ресурс, источник денежных средств. По мнению автора, интеграционный потенциал принимающего сообщества достаточно высок. Межкультурное взаимодействие при этом осложняется дефицитом адекватных интеграционных программ, учитывающих природно-климатические, экономические, социо- и этнокультурные особенности региона.

Ключевые слова:

трудовые мигранты, трудоустройство, этнокультурные установки, ресурсы интеграции, ми грационные процессы, принимающее общество, культурная дифференциация, межкультурное взаимодействие.

\section{Tomaska Alyona Georgievna}

Research Fellow, Arctic History and Ethnic Sociology Department, Institute for Humanities Research and Indigenous Studies of the North, Siberian Branch of the Russian Academy of Sciences

\section{ETHNOCULTURAL RESOURCES FOR THE INTEGRATION OF MIGRANT WORKERS OF YAKUTIA}

Summary:

The study analyzes the ethnocultural resources for the integration of migrant workers in the Republic of Sakha (Yakutia). The paper discusses the factors in particular development of modern migration processes in the region, labor migration structure, statistical data on migratory movement, and the results of a sociological survey. The empirical evidence is analyzed in the context of social communication among migrant workers and the quantitative analytical procedures of the migration sociology of the host community. The research notes that the ethnocultural attitudes of migrant workers are limited in terms of their integration into the host community. The ethnocultural resources for such an integration are constrained by migrants motives and goals focusing on earning money, developing separate, differentiating strategies of interaction with local people restricted by hometown networks. It is perceived by them to be an economic resource, a source of money. In the author's opinion, the integration potential of the host community is quite high. The intercultural interaction between migrants and host communities is complicated by the lack of relevant integration programs tailored to the environmental, economic, social and cultural, and ethnocultural characteristics of the region.

Keywords: migrant workers, employment, ethnocultural attitudes, integration resources, migration processes, host community, cultural differentiation, intercultural interaction.

Своеобразие развития современных миграционных процессов Республики Саха (Якутия) обусловлено такими факторами, как удаленность региона от центра России, экстремальные природно-климатические условия, природные ресурсы, неравномерное территориальное размещение производительных сил, диспропорции в распределении человеческих ресурсов на рынке труда. Промышленность в республике ориентирована на добычу сырья, транспортировку ресурсов, нефтегазопереработку, топливную энергетику и многое другое, создает повышенный спрос на рабочую силу и специфику объемов миграционных потоков в городских поселениях региона.

В сельской местности трудоспособное население занято, как правило, в бюджетной сфере: здравоохранении, образовании, социальном обеспечении, предоставлении коммунальных, социальных и персональных услуг, муниципальном и государственном управлении. Согласно данным Госкомитета Республики Саха (Якутия) по занятости населения, основная проблема низкого уровня трудоустройства жителей заключается в отсутствии вакантных рабочих мест в селе на постоянной основе [1], что провоцирует устойчивый рост внутренней трудовой миграции. 
В структуре миграционных процессов региона доминирует внутрироссийская миграция: более 97 \% мигрантов прибывают из разных областей России. Но с 2000-х гг. преобладает доля внутриреспубликанской миграции из села в город, с тенденцией к росту. Как видно на рисунке 1 , миграционная активность носит сезонный характер. Повышенная интенсивность миграции среди горожан и селян наблюдается в начале летнего сезона. Чрезвычайно высок коэффрициент такой активности у сельских жителей. Самые низкие ее показатели - в холодные зимние месяцы, а также в период транспортной оторванности республики в марте - апреле и октябре - ноябре, во время распутицы на ледовых и водных переправах. Миграционная активность проявляется в сентябре, что, вероятно, связано с началом учебного года. Трудовые мигранты - основная часть миграционного сообщества.

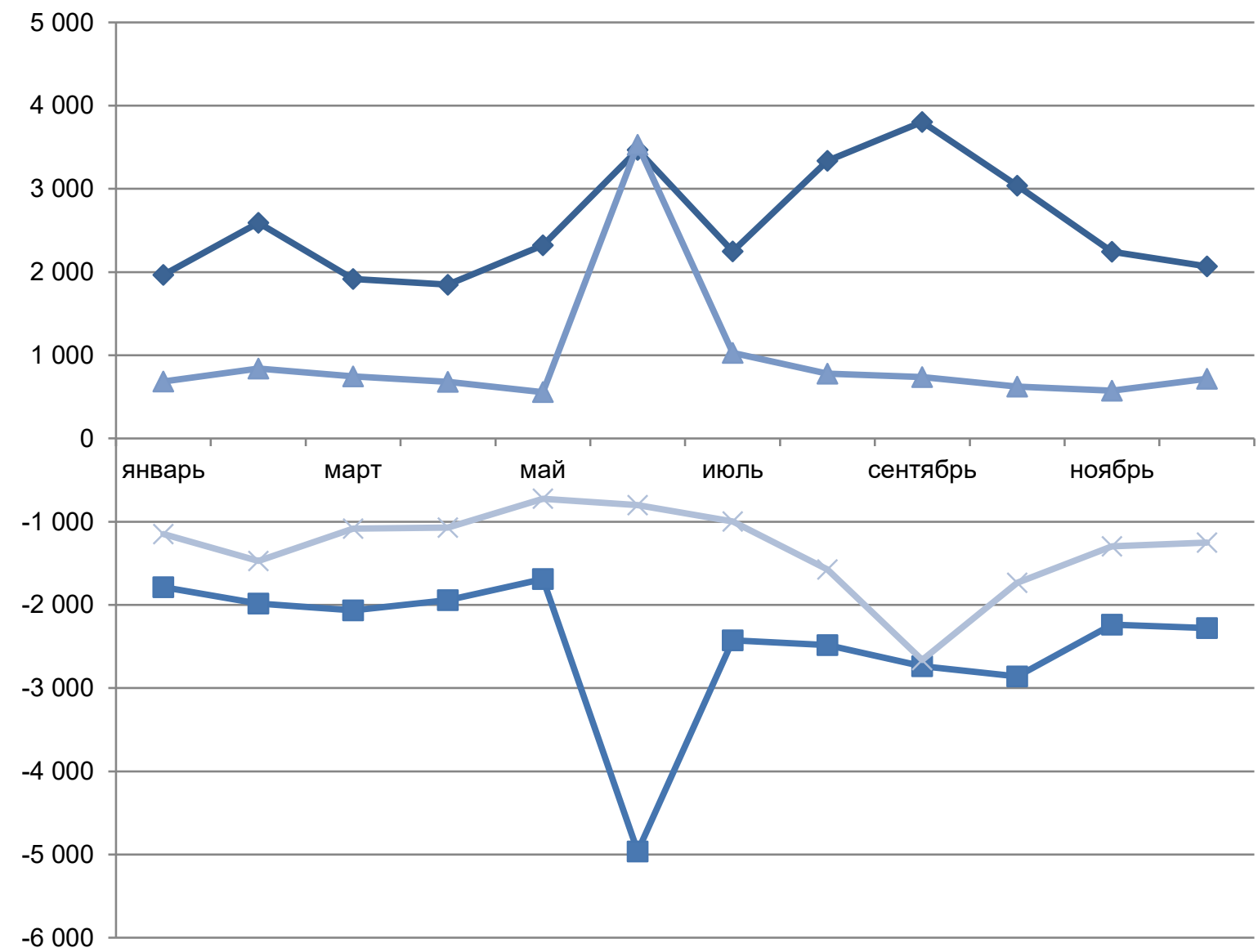

$$
\begin{aligned}
& \smile \text { Городское поселение - прибыло }- \text { Городское поселение - выбыло } \\
& \longleftarrow \text { Сельское поселение - прибыло } \longleftarrow \text { Сельское поселение - выбыло }
\end{aligned}
$$

\section{Рисунок 1 - Миграция населения Республики Саха (Якутия) в 2018 г., чел. [2]}

По данным Министерства внутренних дел, в 2018 г. на миграционный учет в Республике Саха (Якутия) поставлено 73279 иностранных граждан (-9,9\%), в том числе зарегистрировано по месту жительства - 4238 (3,5 \%), поставлено на учет по месту пребывания - 69041 (-10,7 \%). Основной миграционный поток образуют граждане государств - участников СНГ. Наибольшая доля среди прибывших принадлежит гражданам, входящим в общее число въехавших на территорию России из стран ближнего зарубежья: Кыргызстана - 7421 (22,8 \%), Таджикистана - 5848 (17,9), Узбекистана - 3883 (11,9), Армении - $3186(9,8)$ и Украины - 2038 (6,3 \%). Наибольшую долю среди прибывших иностранцев с визовым режимом составляют граждане Китая - 3153 (36,4 \%), Японии $653(7,5)$, Германии - 595 (6,9), США - $279(3,2)$, Франции - $229(2,6)$ и Индии - $226(2,6 \%)$ [3]. 
Следует подчеркнуть, что в республике с целью создания условий, способствующих адаптации, интеграции мигрантов разработана подпрограмма № 5 «Социальная и культурная адаптация и интеграция мигрантов» государственной программы «Развитие гражданского общества и гармонизация межэтнических отношений в Республике Саха (Якутия) на 2018-2022 гг.». Подпрограмма имеет две главные задачи: 1) научно-методическое и информационное сопровождение социальной и культурной адаптации и интеграции мигрантов; 2) реализация мероприятий, направленных на социальную и культурную адаптацию и интеграцию мигрантов.

Именно уровень межличностного взаимодействия, коммуникативное пространство трудовых мигрантов и принимающего сообщества фрормируют новые стандарты поведения и культурные паттерны, расширяют социальные нормы, усложняют социальную среду и представления о мире. Как отметила С. Бенхабиб, «если и в самом деле современная глобальная ситуация порождает настоящие столкновения между культурами, языками и нациями и если ненамеренные результаты таких столкновений сказываются на жизни других, то существует прагматический императив, побуждающий нас понять один другого и вступить в межкультурный диалог» [4, с. 34]. В условиях кризиса, сокращения рабочих мест, ухудшения материального положения, индивидуализации общества, растущего этнокультурного многообразия активный приток качественно иноэтничной миграции чреват ростом социально-экономической напряженности, обострением межнациональных отношений, дестабилизацией локальных социумов. Мигранты (особенно из стран СНГ) все более дистанцируются: хуже знают русский язык, у них другая система образования, ценностей, социокультурных паттернов.

Указанные фракторы определяют актуальность выявления каналов инкорпорации мигрирующей рабочей силы в принимающее общество. В методике исследования проблем интеграции мигрантов учитываются индикаторы, характеризующие экономическую, социальную жизнь индустриального общества, уровень знаний. Анализ эмпирических данных осуществлялся в рамках социально-коммуникативного контекста среди трудовых мигрантов и количественных аналитических процедур социологии миграции принимающего сообщества.

Для сбора первичных данных принимающего сообщества выбрано население города Якутска и поселка городского типа Нижний Бестях в качестве представителей общества-реципиента трудовых мигрантов. Эти населенные пункты отличаются богатым национальным составом и опытом взаимодействия с трудовыми мигрантами. Для анкетного опроса респонденты отобраны по квотной выборке на основе учета структуры генеральной совокупности по полу и возрасту. Кроме того, проведены полуформализованные глубинные интервью в наиболее репрезентированных этнических группах, среди которых киргизы, армяне, таджики и узбеки. Мигрант рассмотрен как член транснациональных социальных сетей, семейных и земляческих. Поиск респондентов происходил по месту работы, информант выбран в соответствии с заданными критериями. Охарактеризованы этнокультурные ресурсы интеграции трудовых мигрантов государств участников СНГ и из стран ближнего зарубежья.

Эмпирическое исследование показало, что 73,3 \% опрошенных представителей местного населения взаимодействуют или взаимодействовали с трудовыми мигрантами. 24,9 \% респондентов испытывают трудности во взаимодействии с ними, т. е. людьми, обладающими иными нормами и ценностями, стереотипами поведения и восприятия. 18,5 \% из них (4,6 \% всех опрошенных) связывают данное обстоятельство с культурными и религиозными отличиями; 35,2 \% (8,8 \%) - с языковым барьером. 53,7 \% представителей местного сообщества (из тех, кто указал на трудности во взаимопонимании с трудовыми мигрантами) можно назвать лицами, готовыми к доверительным взаимоотношениям с «другими». Не случайно П. Штомпка пишет: «Доверие позволяет нам уменьшить неуверенность и предположить, что другие будут поступать выгодно для нас или по крайней мере нейтрально. Мы можем тогда действовать более спокойно, более оптимистично, более свободно, думая, что мир лучше, чем он есть на самом деле» [5, с. 326].

По словам 11,1 \% опрошенных, мигранты не вызывают у них доверия. Как справедливо считает П. Штомпка, риска, создаваемого усложнением социальной среды, невозможно избежать, так как для того, чтобы жить, мы должны вступать во взаимодействие с другими. Следовательно, мы должны постоянно участвовать в игре, делать ставку на те или иные будущие действия наших партнеров. Мы это делаем, проявляя доверие к ним или отказывая им в таком доверии. Доверие и недоверие - это своего рода ресурсы, капитал, который мы приводим в движение, делая свои ставки в этом непрерывном азарте контактов с другими людьми [6]. 12,4 \% респондентов утверждают, что трудовые мигранты привносят этническое и культурное многообразие, у 14,4 \% - дружелюбное, положительное отношение к ним. 29 \% опрошенных убеждены, что мигранты в основном негативно воздействуют, создают проблемы и сложности в социальном пространстве принимающего сообщества. Большинство участников опроса $(63,1$ \%) относятся к ним нейтрально.

При этом мигранты полагаются чаще на сетевой капитал, реальные и потенциальные социальные отношения: способность заводить их и поддерживать с людьми, которые по большей части 
не находятся в близком соседстве, т. е. образовывать и поддерживать сеть [7, с. 360]. Иными словами, миграционное сообщество представляет собой целостную систему со сложной конструкцией, разрабатывающую собственные сепаратные функции взаимодействия с принимающим сообществом. В частности, из интервью с трудовыми мигрантами становится очевидным тот факт, что принимающее сообщество ими рассматривается как экономический ресурс, источник денежных средств. Деньги необходимо заработать, чтобы «отослать семье», «дать детям образование», «купить дом у себя на родине», собрать «на калым» и т. д. По мнению К.С. Мокина, в российских городах мы наблюдаем не просто статистические совокупности иммигрантов или временных трудовых мигрантов, составляющих часть этнокультурной диаспоры, а интенсивно формирующуюся, стремящуюся к кристаллизации и воспроизводству субкультуру мигрантов-прагматиков, рассматривающих принимающую среду преимущественно как экономический ресурс, а не как среду обитания [8, с. 3].

Неформальные, не относящиеся к трудовой деятельности контакты с принимающим сообществом устанавливаются в процессе поиска регистрации и жилья в местах прибытия. Обычно этот вопрос обговаривается еще на родине мигранта. Практически все опрошенные к моменту прибытия имели договоренности о месте временной прописки. Судя по ответам («Да, да, мой дядя уже договорился с одной женщиной, мы ей заплатили, я ее не видел, я там не жил, мы снимаем квартиру»), используются не всегда легитимные способы. Хотя авторитет земляков, вступивших в успешные, на их взгляд, личные взаимодействия с принимающим населением, решающие на данном этапе их жизненные проблемы, оценивается высоко.

Процесс трудоустройства, как правило, определяется общинными связями, присоединением к укрепившимся группам земляков, которые обеспечивают им подготовительные процедуры в принимающей стороне и одновременно поддерживают отношения с родиной и мигрантами-соотечественниками. Более того, «цепочка» их трудовой деятельности поддерживается земляческими сетями, несомненно снижающими риски в пространстве неопределенности и конкуренции на рынке труда другой страны. Например, большую часть собственников овощных лавок, продавцов овощами и фрруктами в Якутске составляют этнические узбеки из Кыргызстана. Они не закупают овощи в оптовых базах города, а привозят их из Новосибирска и городов Дальнего Востока, приобретая продукцию у земляков, которые с участием соотечественников доставляют ее из Китая, иных среднеазиатских стран. Торговцы товарами народного потребления (киргизы) на рынках Нижнего Бестяха и Якутска получают этот товар по аналогичной схеме из разных городов России и соседних стран.

Установление позитивных социальных, личных контактов с местным населением обусловлено для мигрантов их целеполаганием - зарабатыванием денежных средств. Так, на встрече председателей и лидеров некоммерческих организаций из г. Якутска с заместителем руководителя Федерального агентства по делам национальностей России представитель киргизской национально-культурной общины сетовал, что их соотечественники вынуждены заключать фиктивные браки с местными женщинами ввиду дороговизны патента на работу.

Вопросы о знании культуры, языка, обычаев принимающей стороны вызывают в большинстве случаев легкое недоумение у мигрантов. Культурная диффреренциация представляется им более органичной и естественной. Трудовые мигранты считают, что им легче адаптироваться в Якутии, поскольку они внешне мало отличаются от коренного населения. В то же время анкетный опрос местных жителей показал, что, по мнению 4,6 \% респондентов, мигранты вызывают межкультурные конфлликты, не приспосабливаются к региональным социокультурным условиям. Важно отметить, что у мигрантов с детьми наблюдается больше мотивов-целей к культурной интеграции. Они стараются найти точки соприкосновения с местным населением: родителями (в детских садах и школах), медицинским персоналом (в учреждениях здравоохранения). Ходят в кино, музеи, на концерты ради детей. Но посещение театров и библиотек ими ни разу не упоминалось.

В интервью сотрудники Ресурсного образовательно-методологического центра в сфере национальных отношений Дома дружбы народов имени А.Е. Кулаковского признаются, что наиболее существенные проблемы в их работе вызваны отсутствием интереса к культурной интеграции у мигрантов, практически не поддерживающих контакты с общественными национальными объединениями. Трудовые мигранты всегда заняты работой, и даже когда их приглашают на мероприятия, предусматривающие обеспечение сетевой связи между общественными объединениями, оказание им информационной, научно-методической, консультационной поддержки. С большим трудом их можно пригласить только на бесплатные юридические консультации.

Таким образом, этнокультурные установки трудовых мигрантов с точки зрения их интеграции в принимающее сообщество ограничены отсутствием установок на интеграцию, проявлением их целеполагания (исключительно зарабатыванием денег), разработкой в трудовой деятельности и этнокультурных отношениях сепаратных, ограниченных земляческими сетями, дифференцирующих стратегий взаимодействия с местным населением. Оно воспринимается ими как экономический ресурс, источник денежных средств. 
Анализ материалов опроса местных жителей позволяет сделать вывод о том, что интеграционный потенциал принимающего сообщества достаточно высок. В частности, подтверждением этой мысли служат интервью с трудовыми мигрантами. Из их содержания следует, например, что в период акций протеста против мигрантов в марте 2019 г., после того как в СМИ и социальных сетях распространилась инфрормация об уроженцах Средней Азии, подозреваемых в похищении и изнасиловании женщины, часть мигрантов-мужчин (водители автобусов, продавцы овощных ларьков и др.), опасаясь за свою безопасность, не вышли на работу. Однако мигрантыженщины в учреждениях общепита, сервиса, торговли продолжали работать. Кроме того, один из продавцов, уроженец Киргизии, торгующий на рынке, сообщил в интервью, что местные клиенты много раз звонили, выражая слова поддержки и говоря о добром расположении.

Межкультурное взаимодействие мигрантов и принимающего сообщества осложняется дефицитом адекватных интеграционных программ, предусматривающих природно-климатические, экономические, социо- и этнокультурные особенности региона. Трудности такого взаимодействия в новой среде во многом определяются односторонностью миграционной политики в целом и этнокультурным расслоением в частности. Процесс интеграции мигрантов должен предусматривать гражданское воспитание и образование акторов, разработку дополнительных методов и механизмов интеграции в миграционной политике, призванных снижать социальные риски, перераспределение трудовых ресурсов.

\section{Ссылки:}

1. Уровень безработицы в Якутии выше, чем в среднем по России [Электронный ресурс] // Информационно-аналитический портал SakhaNews. 2018. 24 янв. URL: http://www.1sn.ru/204575.html (дата обращения: 08.06.2019).

2. Миграция населения [Электронный ресурс] // Территориальный орган Федеральной службы государственной статистики по Республике Саха (Якутия). 2015. 18 мая. URL: http://sakha.gks.ru/wps/wcm/connect/rosstat ts/sakha/ru/statistics/population/4fb8d980486a27f3ba0dfaf7eaa5adf2 (дата обращения: 08.06.2019).

3. Информационно-аналитическая записка о результатах деятельности органов внутренних дел по Республике Саха (Якутия) за январь - декабрь 2018 г. [Электронный ресурс] // Министерство внутренних дел по Республике Саха (Якутия). 2019. 13 февp. URL: https://14.xn--b1aew.xn--p1ai/slujba/отчеты-должностных-лиц-2/отчеты-мвд-по-республике-сахаякутия-/item/16306203 (дата обращения: 09.06.2019).

4. Бенхабиб С. Притязания культуры. Равенство и разнообразие в глобальную эру : пер. с англ. М., 2003. 289 с.

5. Штомпка П. Социология. Анализ современного общества : пер. с пол. М., 2005. 664 с.

6. Там же. С. 326

7. Урри Дж. Мобильности. М., 2012. 576 с.

8. Мокин К.С. Стратегии адаптации этнических миграционных сообществ в поликультурной среде : автореф. дис. .... д-ра социол. наук. Саратов, 2007. 40 с.

\section{References:}

Benhabib, S 2003, The Claims of Culture. Equality and Diversity in the Global Era, Moscow, 289 p., (in Russian). Mokin, KS 2007, Adaptation Strategies of Ethnic Migratory Communities in a Multicultural Environment, D.Phil. thesis abstract, Saratov, 40 p., (in Russian).

Sztompka, P 2005, Sociology. Analysis of Modern Society, Moscow, 664 p., (in Russian).

Urry, J 2012, Mobilities, Moscow, 576 p., (in Russian). 